\title{
Importance of mental capacity: time for greater attention and action
}

\author{
Peng Soon $\underline{N g}^{1}$, MBBS, MRCP, Lye Poh Aaron $\underline{\text { Ang }}{ }^{2}$, MMed(Psy), MRCP, Nagaendran $\underline{K a n d i a h}^{1,3}$, FRCP, FAMS
}

\section{INTRODUCTION}

The dramatic case of a wealthy widow suffering from dementia who previously handed over control of her significant assets to a tour guide has put the spotlight on the Lasting Power of Attorney (LPA) scheme. (1) Given the legal implications of the case, it has also unnerved fellow medical colleagues who are LPA certificate issuers. The crux of the issue is the determination of mental capacity. This matter is all the more pressing, given Singapore's ageing population with its increasing life expectancy, ${ }^{(2)}$ and the associated increasing prevalence of dementia and psychiatric, medical and neurological comorbidities. All these conditions are intimately linked to the loss of decision-making capability. From a broader perspective, the issue of determining mental capacity is the concern of not only the accredited LPA certificate issuer, but also the medical practitioner, who needs to obtain valid informed consent from the patient. This article discusses some of the challenges, concerns and misconceptions concerning the assessment of mental capacity, and serves to provide guidance to the busy clinician.

\section{THE MENTAL CAPACITY ACT}

The enactment of the Mental Capacity Act (MCA) in 2010 (3) provides a statutory framework for assessing decision-making capacity. During the evaluation of a patient who may lack mental capacity, one must apply the following five statutory principles of the MCA:(4)

1. A person must be assumed to have capacity unless it is established that he lacks capacity.

2. A person is not to be treated as unable to make a decision unless all practicable steps to help him to do so have been taken without success.

3. A person is not to be treated as unable to make a decision merely because he makes an unwise decision.

4. An act done, or a decision made, under this Act for or on behalf of a person who lacks capacity must be done, or made, in his best interests.

5. Before the act is done, or the decision is made, regard must be had to whether the purpose for which it is needed can be as effectively achieved in a way that is less restrictive of the person's rights and freedom of action.

These aforementioned principles cannot be overemphasised and will be reiterated throughout the article.

\section{ASSESSING MENTAL CAPACITY}

Mental capacity, which is the medical equivalence of competence, is ultimately a legal judgement. Nonetheless, due to the nature of their work, physicians are often called upon to make a clinical judgement on a patient's decision-making capacity. The courts will, however, make the final decision to accept or reject the physician's conclusions.

Prior to the assessment of mental capacity, the physician should understand the underlying reason and context in which the decisions are to be taken. In some cases, it may alert the physician to potential underlying or hidden agendas and medicolegal implications, thus enabling him or her to direct the assessment with prudence. Special care should be taken whenever it involves vulnerable persons such as the elderly, intellectually disabled or mentally ill. Potential red flags with regard to the LPA include applications that are initiated and strongly advocated for by someone other than the donee (i.e. risk of coercion), or the nomination of an uncommon donee (i.e. non-family members or relatives).

Next, the physician focuses on determining whether the patient has the mental capacity to make a specific decision. This is done by applying the two-stage test. ${ }^{(5)}$ The first stage involves taking the patient's history and performing assessments to determine whether there is an underlying impairment of or disturbance in the functioning of the mind or brain. Common examples of impairment or disturbance include dementia, stroke, encephalitis, brain tumour, traumatic head injuries, delirium and mental illnesses such as schizophrenia and depression. If the patient is found to have an underlying impairment or disturbance at the first stage, the second stage will evaluate its impact on the patient's decisional capacity at the point of decision-making. Thus, the test is both time- and decision-specific. A blanket assessment of incapacity is not acceptable except in cases of severe dementia, permanent vegetative state and permanent global aphasia.

An individual is only determined to be unable to make a decision for himself if he is unable to meet the following criteria ${ }^{(6)}$ (best remembered using the suggested mnemonic "CRRC"):

- Comprehend the information relevant to the decision;

- Remember that information;

- $\quad$ Reason with that information during the process of making the decision; or

- Communicate his decision (whether by talking, using sign language or any other means).

${ }^{1}$ Department of Neurology, National Neuroscience Institute, Tan Tock Seng Campus, ${ }^{2}$ Department of Psychological Medicine, Tan Tock Seng Hospital, ${ }^{3}$ Duke-NUS Graduate Medical School, Singapore

Correspondence: Dr Peng Soon Ng, Associate Consultant, Department of Neurology, National Neuroscience Institute, 11 Jalan Tan Tock Seng, Singapore 308433. peng_soon_ng@nni.com.sg 
It is essential that "a person is not to be treated as unable to make a decision unless all practicable steps to help him do so have been taken without success". ${ }^{(4)}$ These steps include, but are not limited to, providing a translator to minimise the language barrier and assessing the patient at a time when he is in his best cognitive state. Sufficient effort should be undertaken to make available communication or physical aids for a patient with physical, hearing or visual impairments, so as to ensure that the patient's ability to understand or communicate his decision is optimised. In complex and specialised procedures such as those involving medical (e.g. treatments or surgeries) or legal (e.g. LPA) matters, content experts may be needed to provide relevant information to the person before the mental capacity assessment. In spite of these best efforts, it is extremely challenging to ascertain capacity if communication is limited to 'yes' or 'no' answers, especially with regard to complex and/or high-risk (or high-stakes) decisions. Some helpful questions to determine mental capacity include:

1. Test for comprehension: "Tell me what you know about the LPA?" or "Do you know what has been wrong with your health since admission?"

2. Test for retention of information: "Now that I have explained the risks and benefits of the procedure/test/LPA, what do you think will happen if you do not have the procedure/test/LPA?"

3. Test for reasoning behind the decision: "Tell me why and how you reached this decision."

An assessment of mental capacity is thus similar to a full medical consultation. As such, it can be argued that the physician who knows the patient best may be in the best position to perform this assessment. The decisions made and the process used to reach those decisions should be clearly documented in the patient's case notes.

\section{CHALLENGES, MISCONCEPTIONS AND CONCERNS}

\section{Temporary and fluctuating mental capacity}

Some patients may suffer from impaired mental capacity, but based on medical knowledge, have a high likelihood of improvement over time once the underlying problem is treated or resolved. Examples of conditions that temporarily impair mental capacity include subdural haematomas, brain tumours and septic encephalopathy. Some patients suffer from fluctuating mental capacity, in which their mental capacity changes from time to time. These include patients with mild dementia, delirium and schizophrenia. In such cases, the physician needs to ascertain if the decision to make an LPA can be delayed. If so, the mental capacity assessment should be deferred to a later date, when the patient has recovered from the underlying medical condition or when the patient is in his best possible state after medical optimisation. However, if the decision needs to be made due to the urgency of the medical situation, treatment decisions should be made based on the patient's best interest.

\section{Unwise decisions}

Occasionally, there is a fine line between unwise decisions and a lack of capacity due to the inability to weigh information as part of the decision-making process. This issue often arises when the patient disagrees with his physician's treatment plan and the decisional capacity of the patient is thus challenged. In such instances, an evaluation is required to establish whether the patient is labouring under a medical (e.g. delirium) or psychiatric (e.g. depression) condition, where cognition is impaired (i.e. impairment of or disturbance in the functioning of the mind or brain). In the absence of such an impairment or disturbance, the patient is entitled to make unwise decisions, and this does not constitute impaired mental capacity. Such decisions are usually consistent with the patient's character and core values. However, not all patients have well-articulated values and goals, and some may even have multiple conflicting goals; their decision may be consistent with some goals but not with others. Therefore, a physician needs to be aware of this and should, as far as possible, treat the patient in a manner that is least restrictive of his basic rights and freedom of action.

\section{Using capacity assessment tools}

There are many different instruments for assessing capacity. Sessums et al's systematic review found that Aid to Capacity Evaluation (ACE) with robust likelihood ratios is one of the best available tools to assist physicians in making an assessment of medical decision-making capacity. ${ }^{(7)} \mathrm{ACE}$, a semi-structured interview that assesses patients using questions specifically tailored to an individual's diagnosis and treatment, has high expert agreement when evaluated against a gold standard (forensic psychiatrist) and can be performed within 10-20 minutes in an office setting. ${ }^{(8)}$ Other well-known validated tools such as the MacArthur Competence Assessment Tool for Treatment (MacCAT-T) ${ }^{(9)}$ despite its excellent inter-rater reliability and ease of use, was not included in Sessums et al's review, as it does not have a gold standard comparator. In the same systematic review, the authors found that the Mini-Mental State Examination (MMSE), which is not designed to assess incapacity, is most commonly used in clinical practice to evaluate a patient's mental capacity. ${ }^{(7)}$

It must be remembered that, while such tests provide an overall impression of mental state, there is no cut-off score to indicate mental incapacity. An MMSE score below 20 usually suggests significant cognitive impairment and a lack of capacity for rational decision-making. However, even in this state, decision-making capacity specific to the issue at hand must be explored before mental incapacity is certified. Impairments picked up on cognitive testing can support, but cannot be the sole basis for determining, the lack of decision-making capacity. Therefore, we opine that, despite the many reliable and helpful mental capacity assessment tools available, a good direct assessment of the patient's understanding of the issue at hand, retention of the information provided and reasoning behind his decision, as well as the physician's conscientious exercise of clinical judgement, are essential for the determination of mental capacity. A semistructured clinical interview format, as detailed by Sahadevan et al in their assessment of decision-making capacity in dementia patients, is a useful guide that expounds on these principles. ${ }^{(10)}$ 


\section{Best interest principle}

It is a common misconception that relatives have the right to make decisions on behalf of a patient who lacks mental capacity. Unless appointed by the patient as a donee under the LPA, or by the court as a Court Appointed Deputy, relatives have no such legal rights. ${ }^{(11)}$ In a situation where the patient lacks mental capacity and a decision has to be made, the physician should make the decision based on the best interest principle. 'Best interest' is often determined in a specific situation after taking into account the patient's values and preferences, if they are known. If not, the views of persons who know the patient well (usually the patient's relatives) are crucial in the decision-making process. The best available and least restrictive option in the specific situation should be used. Rarely are judgements on the patient's best interest made based on the physician's values and preferences. To safeguard against this, the physician has to recognise that, although he or she may be in the best position to make decisions in the patient's best medical or surgical interest, the 'expertise' of the family, carer, donee, medical social worker and others is still required to determine the other aspects of a patient's best interest (e.g. social, financial). In some circumstances, it may also be appropriate to obtain a second opinion from another physician or the hospital ethics committee; this ensures that the decision is not simply a reflection of the physician's own personal views.

\section{Emergency situation and life-sustaining treatments}

In an emergency situation or a serious medical condition where a decision concerning life-sustaining treatment needs to be made, it is the physician who must make the decision, regardless of the presence of a personal welfare donee appointed by the patient under the LPA. ${ }^{(12)}$ This is because, in these situations, it is often impractical and inappropriate to delay treatment in order to wait for the patient to make a decision or consult with appointed deputies. However, such decisions must be made in the patient's best interest, and it is still good practice and common sense for the physician to attempt to communicate with the patient's relatives to keep them informed of what is happening.

\section{CONCLUSION}

It can be seen that the mental capacity assessment is no different from the usual proper clinical evaluation, which includes thorough history-taking and relevant assessments. Most cases of mental capacity determination are straightforward, if the aforementioned points are considered. This holds true for the majority of LPA certification processes. The saga involving the wealthy widow serves to remind the medical practitioner of the importance of good clinical assessment and documentation. Continuing medical education activities, such as the Annual National Medicolegal Seminar 2014 on mental capacity, jointly organised by the Medico-Legal Society of Singapore and
Singapore Medical Association, helped to develop awareness and enhance the professional skills of doctors in mental capacity assessments. ${ }^{(13)}$ In addition, The Code of Practice by the Office of the Public Guardian, which provides guidance for practitioners caring for people lacking mental capacity, ${ }^{(14)}$ and Menon's local review on the implications of the MCA for doctors and patients are invaluable resources for clinicians. ${ }^{(15)}$ When faced with challenging cases, there will always be a friendly psychiatrist, neurologist or geriatrician to offer a helping hand.

\section{REFERENCES}

1. Hoe PS. Tussle over $\$ 40 \mathrm{~m}$ assets: Widow capable of making decision on assets. The Straits Times 2014 Nov 24. Available at: http://www. straitstimes.com/news/singapore/courts-crime/story/family-court-ruleswealthy-widow-can-revoke-lpa-china-tour-guide-2. Accessed February 20, 2015.

2. Department of Statistics Singapore. Population Trends 2014. Available at: http://www.singstat.gov.sg/publications/publications-and-papers/ population-and-population-structure/population-trends. Accessed February 20, 2015.

3. Singapore Statutes Online. Mental Capacity Act (Chapter 177A). Revised edition 2010. Available at: http://statutes.agc.gov.sg/aol/search/display/view. w3p;query=Docld\%3A7f933c47-8a34-47d1-8d0a-0a457d6fa1c2\%20 $\% 20$ Status $\% 3$ Ainforce $\% 20$ Depth $\% 3 \mathrm{~A} 0 ;$ rec $=0 ;$ whole=yes. Accessed August 16, 2015.

4. Singapore Statutes Online. Mental Capacity Act (Chapter 177A). Revised edition 2010. Section 3. Available at: http://statutes.agc. gov.sg/aol/search/display/view.w3p;query=Docld\%3A7f933c478a34-47d1-8d0a-0a457d6fa1 c2\%20\%20Status \%3 Ainforce $\% 20$ Depth\%3A0;rec=0; whole=yes\#pr3-he-. Accessed August 16, 2015.

5. Singapore Statutes Online. Mental Capacity Act (Chapter 177A). Revised edition 2010. Section 4(1). Available at: http://statutes.agc. gov.sg/aol/search/display/view.w3p;query=Docld\%3A7f933c478a34-47d1-8d0a-0a457d6fa1c2\%20\%20Status\%3Ainforce $\% 20$ Depth\%3A0;rec=0; whole=yes\#pr4-he-. Accessed August 16, 2015.

6. Singapore Statutes Online. Mental Capacity Act (Chapter 177A). Revised edition 2010. Section 5. Available at: http://statutes.agc. gov.sg/aol/search/display/view.w3 p; query=Docld\%3 A7f933c478a34-47d1-8d0a-0a457d6fa1c2\%20\%20Status\%3Ainforce $\% 20$ Depth\%3A0;rec=0; whole=yes\#pr5-he-. Accessed August 16, 2015.

7. Sessums LL, Zembrzuska H, Jackson JL. Does this patient have medical decision-making capacity? JAMA 2011; 306:420-7.

8. Etchells E, Darzins P, Silberfeld M, et al. Assessment of patient capacity to consent to treatment. J Gen Intern Med 1999; 14:27-34.

9. Grisso T, Appelbaum PS, Hill-Fotouhi C. The MacCAT-T: a clinical tool to assess patients' capacities to make treatment decisions. Psychiatr Serv 1997; 48:1415-9.

10. Sahadevan S, Chin JJ, Yap MN, Yeoh OE. Assessing decision-making capacity in dementia patients: a semi-structured approach. Ann Acad Med Singapore 2003; 32:749-55.

11. Re T (Adult: Refusal of Treatment), [1993] Fam 95 at 103.

12. Singapore Statutes Online. Mental Capacity Act (Chapter 177A). Revised edition 2010. Section 13(8). Available at: http://statutes.agc. gov.sg/aol/search/display/view.w3 p; query=Docld\%3 A7f933c478a34-47d1-8d0a-0a457d6fa1c2\%20\%20Status\%3Ainforce $\% 20$ Depth\%3A0;rec=0; whole=yes\#pr13-he-. Accessed August 29, 2015.

13. The Annual National Medicolegal Seminar 2014. Understanding mental capacity - concepts and current practice. Available at: https://sma.org.sg/ academy/OtherCourseDetail.aspx?CID=14\&ID=126. Accessed February 21,2015

14. Office of the Public Guardian Singapore. Code of Practice. Mental Capacity Act (Chapter 177A). Available at: https://www.publicguardian.gov.sg/ Portals/0/Guides/Code\%20of\%20Practice_Jan15\%20(for\%20Web).pdf. Accessed August 16, 2015.

15. Menon S. The mental capacity act: implications for patients and doctors faced with difficult choices. Ann Acad Med Singapore 2013; 42:200-2. 